\title{
1 IN MEMORIAM
}

CUAJ honours its members and friends who have passed away. We invite colleagues of the deceased to submit brief remembrances. Please limit your notice to 200 words. Send your notice to journal@cua.org or fax it to 514-395-1664.
Cite as: Can Urol Assoc J 2014;8(11-12):452. http://dx.doi.org/10.5489/cuaj.2601

Published online December 15, 2014.

\section{Dr. Bill Lakey}

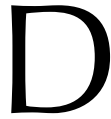

r. Bill Lakey was raised in Medicine Hat Alberta. He graduated from the University of Alberta in 1953 where he also completed his surgical residency. In 1957, he was awarded the Royal College Medal for Surgical Research. He completed a Urology residency training at the University of Michigan, Ann Arbor. During his residency in Michigan, he became interested in chronic renal failure therapy and kidney transplant surgery.

He returned to the University of Alberta in 1960 as the first full-time urologist. He assisted Dr. Lionel McLeod in the establishment of

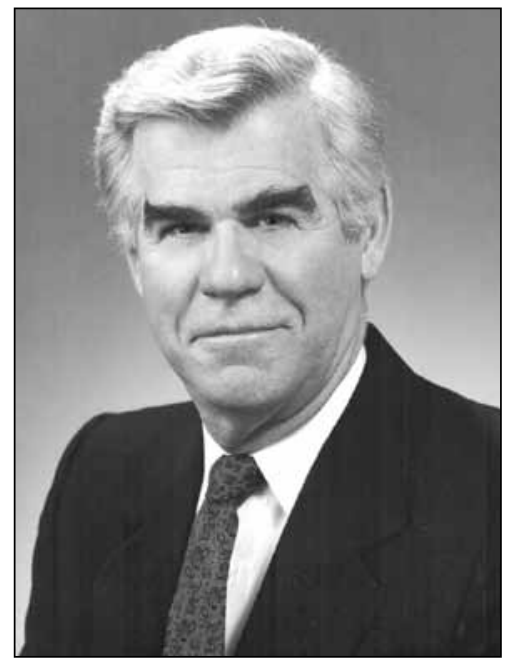
the first Chronic Hemo-Dialysis Program in

Canada in 1961. In 1967, he performed the first kidney transplant at the University Hospital. With the help of Dr. Rex Boake, Dr. John Dossetor and Dr. Phil Halloran, he developed the Kidney Transplant Program at the University Hospital. Dr. Lakey was appointed Director of the Division of Urology in 1976, a position he held until 1986.

Dr. Lakey participated in the activities of the Canadian Urologic Association for many years, serving as Secretary for 5 years and as President in 1980. Dr. Lakey represented the Urology Division for 8 years as a member of the Council of the Royal College of Physicians and Surgeons of Canada. He was elected to the membership of the prestigious American Association of Genitourinary Surgeons in 1974. In June of 1981, he was awarded the Outstanding Achievement Award of the Canadian Urological Association at its Joint Meeting of the American Urologic Association and Canadian Urological Association in Toronto. He was also awarded the Distinguished Service Award for the Department of Surgery at the University of Alberta in 1993. 